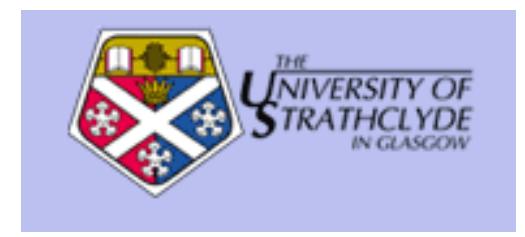

Tierney, Daniel and Gallastegi, Lore (2005) Where are we going with primary foreign languages? Language Learning Journal, 31. pp. 41-54. ISSN 0957-1736

http://eprints.cdlr.strath.ac.uk/3228/

Strathprints is designed to allow users to access the research output of the University of Strathclyde. Copyright ( $)$ and Moral Rights for the papers on this site are retained by the individual authors and/or other copyright owners. Users may download and/or print one copy of any article(s) in Strathprints to facilitate their private study or for non-commercial research. You may not engage in further distribution of the material or use it for any profitmaking activities or any commercial gain. You may freely distribute the url (http://eprints.cdlr.strath.ac.uk) of the Strathprints website.

Any correspondence concerning this service should be sent to The Strathprints Administrator: eprints@cis.strath.ac.uk 


\title{
Where are we going with primary foreign languages?
}

\author{
Daniel Tierney and Lore Gallastegi \\ Daniel Tierney, University of Strathclyde and Lore Gallastegi, University of Strathclyde and \\ Open University
}

\begin{abstract}
This article considers Modern Languages in the Primary School (MLPS), which have reached a crucial stage in both England and Scotland. It looks at developments in the two countries and considers these against both a historical and European background. The authors, drawing on their practical experience, put forward some of the key points to be addressed as well as making the case for certain approaches, based on their experience and the available literature.

The article begins with a brief update of the situation in Scotland and England, before considering the aims and objectives of both. It also looks at the debate about whether an early start is beneficial and considers methodology. Particular aspects to be considered include Knowing about Language and the balance between the four skill areas of Listening, Speaking, Reading and Writing.

The authors conclude the article by drawing out some issues on which there might be a consensus but at the same time identify the need for a national debate on what we are trying to achieve at a time when significant funding is being invested.
\end{abstract}

\section{THE SITUATION IN SCOTLAND}

Modern Languages in the Primary School (MLPS) have reached a crucial stage in both England and Scotland. Although the two countries are at different stages in their development there are critical issues to be addressed.

Scotland embarked on foreign languages in primary schools once again in 1989 with the establishment of some pilot projects. The then Secretary of State announced that he wished:

to examine the case for beginning the study of a modern European language in primary school. He is aware that early experiments in the field were not a success and he considers that a better outcome may be achieved with more careful planning, an adequate supply of trained teachers, and an appropriate level of resources committed to the project. (Scottish Office, 1989)

In 1993, following successful piloting, Scotland moved to what became known as the generalisation phase, where the programme would gradually be rolled out to include every primary school in Scotland. The Education Minister announced that:

building on these foundations (i.e. the National and Regional Pilots), we now propose that all Scottish Primary Schools should offer teaching in a modern European language: French, German, Spanish or Italian ... I intend that the SOED, in consultation with other interested parties, should devise an implementation strategy, including training arrangements, which would bring to larger numbers of primary teachers the linguistic skills they need to introduce a modern language into the Primary Curriculum. (Scottish Office, 1993)

By the late 1990s Scotland had achieved its initial objectives. Initially, the national undertaking was to train one teacher per primary school, equivalent to approximately 2300 teachers. On the advice of the National Steering Committee for Modern Languages in the Primary School (MLPS) this target was amended to one teacher per two classes in the final two years of primary school (P6 and P7), the total number of classes at these stages being 5511, and thus the revised target for the number of teachers to be trained was 2755. In the period 1993-1999 there were six phases of training courses, as a result of which some 4500 teachers completed the 27-day national training programme, clearly exceeding the initial and amended targets.

Following a report from Her Majesty's Inspectors based on inspections of 41 schools, but also taking account of reports from 150 schools visited by our colleague, John De Cecco and one of the authors as National Development Officers, MLPS was referred to a Ministerial Action Group on Languages set up by the then minister, Helen Liddell MP, in 1998. This Inspectorate Report found the key strengths of modern languages in primary schools included:

- the enthusiasm and motivation of almost all pupils;

- high attainment by some very able pupils;

- examples of good or very good teaching in $85 \%$ of schools; and

- very good organisation of resources and classroom display.

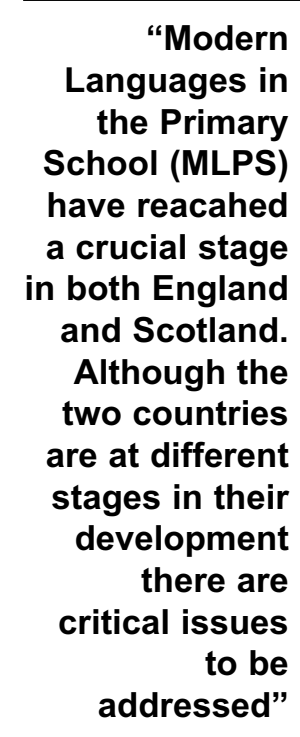
Address for
correspondence:
Daniel Tierney
University of Strathclyde
Room 54b, David Stow Building
76 Southbrae Drive Glasgow G13 1PP

email: d.tierney@strath.ac.uk 
But the major weaknesses identified in this report should be addressed by primary schools, headteachers and education authorities to ensure that:

- the study of a modern language is included in the curriculum of all pupils in $\mathrm{P} 6$ and $\mathrm{P} 7$;

- time allocated to foreign languages is broadly consistent within and across schools;

- courses include elements of reading and writing;

- appropriate links are made with other curricular areas, particularly English language, and with the local secondary school;

- teachers record pupils' attainment; and

- appropriate time and support is provided for staff teaching languages to maintain their skills, prepare work and consult with other teachers. (HMSO, 1998)

In 2000 the Ministerial Action Group made some recommendations with regard to MLPS. They included an entitlement:

likely to consist of students taking one and the same modern language at P6 and P7 for 75 minutes per week, amounting to approximately 100 hours at primary school, followed by some 400 hours at secondary school from S1 - S4 inclusive. (Scottish Executive, 2000)

Thus, Scotland reached a critical juncture. MLPS moved into the mainstream curriculum, clear objectives had been defined and a critical mass of generalist primary teachers had been trained. Early surveys of pupil achievement were also encouraging. In Scotland since 1983 regular Assessment and Achievement Programme (AAP) surveys have been carried out in English language, Maths and Science.

The surveys are intended to inform SEED, education authorities, teachers and other interested parties about the achievement of pupils in the different aspects of the curriculum. (Scottish Executive, 2003)

In 1998 the first Modern Languages pilot AAP survey was conducted by a team from the University of Stirling, followed by a full survey in 2001 concentrating on French and German in P7 and S2. In P7, listening, speaking and Knowledge about Language (KAL) were assessed, while in S2 reading and writing were also included. The pupils' attainment was measured according to level descriptors set out in the Modern Languages 5-14 National Guidelines (Learning and Teaching Scotland, 2000). The survey found that "S2 students have made good progress in relation to the performance of P7 students". In terms of listening, S2 students appeared to have a more extensive repertoire of vocabulary and basic structures, although little difference was found in terms of their "ability to deal with the unexpected". In speaking, S2 pupils had a wider range of vocabulary, although both P7 and S2 pupils relied "heavily on known chunks". Reading and writing were assessed only in S2, and reading proved to be the pupils' strongest skill while writing was their weakest.
In their conclusions, the team undertaking the survey stated that:

this survey provides evidence that provision for languages in the primary school is enabling most students (over four-fifths) to achieve the most basic level of competence (i.e. Level C), and some (around a third) to achieve more than this. Secondary students have consolidated the basics of the language they are studying, and, in many cases, are widening their linguistic repertoire, with more extensive vocabulary, phrases and structures than at primary level. Some secondary students are beginning to become more creative in their use of the language they are studying. (Scottish Executive, 2003)

There is good reason for satisfaction with what has been achieved to date both in terms of implementation and achievement. However, there remain crucial issues to be addressed:

- How is the provision of teachers to be sustained?

- How do we sustain the linguistic competence and confidence of the primary generalists, some of whom were trained in the 1990 s?

- What pre-service provision is to be made? Some ten years after this was first identified as one of the issues to be considered, it is yet to be resolved. Indeed, Recommendation 10 of the Ministerial Action Group was to make a Modern Language a part of the core in all ITE programmes in Scotland. This recommendation was referred to the general national review of ITE programmes in Scotland but no resolution has emerged.

- How do we improve continuity and progression across the country? Some examples of good practice have been found in some clusters, but not throughout the country. Indeed, transition from primary to secondary is patchy. In a few local authorities all primaries are to follow an agreed programme. However, in most areas it is left to the individual school and it can vary from considerable liaison and transfer of information to little or no contact between the two sectors with regard to modern languages.

- What do we do about the related problem of diversification? In some cases, due to placing requests or relocation, pupils are not guaranteed continuity of the language they studied at primary. In other cases, the secondary has discontinued its policy of diversification with obvious consequences for primary schools offering one of those languages. A further complication is that the majority $(76 \%)$ of primary teachers were trained in French, and in some clusters this has had consequences for the existing diversified provision in the secondary.

- What has been achieved in terms of the development of linguistic competence? We now have significant cohorts which have gone through MLPS and Standard Grade / Higher. What linguistic benefits have we achieved? There 
is as yet no evidence that Scotland is seeing an increased level of competence post 16 as a result of MLPS.

- Are our aims and objectives correct?

- Are we starting at the right age?

- Is our methodology the correct one?

- What are the advantages/disadvantages of the two models? In some cases the teacher teaches her/his own class. However, there is an increasing tendency towards the 'drop in' model whereby the trained MLPS teacher takes the P6 or P7 while that teacher takes her/his class.

\section{THE SITUATION IN ENGLAND}

In the 1960s a Pilot Scheme for teaching French in primary schools was introduced in England and Wales (Schools Council, 1966). Pupils aged 8 were taught French by primary teachers who had received training both in methods and in the French language in France and in the UK. Secondary teachers had also been trained to teach pupils coming with different abilities and competences from primary schools. Authorities worked with schools and teachers in order to ensure primary-secondary continuity and in order to support teachers integrating the French language into the Primary Curriculum.

In 1974, Burstall and her colleagues published a report on the evaluation of the Pilot Scheme. The team found that:

- the introduction of French did not exert any significant influence on children's other attainments;

- at the beginning of the FL learning experience all pupils seemed to take advantage of it, but this became more selective as more demanding skills and activities were introduced;

- pupils taught French at age 8 seemed to gain in attitude rather than in mastery;

- no single method was appropriate for all pupils;

- there were problems that had not been solved, such as the provision of suitably qualified teachers, primary-secondary continuity and the presence of pupils with different aptitude and achievement levels being taught to achieve the same goals.

Based on their evaluation, the team led by Burstall concluded "against a possible expansion of the teaching of French in primary schools" and the government withdrew the funding.

Since then, England has taken a more cautious approach and watched the Scottish experiment with interest. There have been many notable local initiatives, but the provision across the country has been somewhat patchy. As Sharpe (2001) pointed out, "it is unsurprising perhaps that for the time being the picture emerging is one of diversity and some uncertainty."

Sharpe also referred to that stage of development in England "as a chaotic and uncoordinated area of school provision".

In the 1990s, the government south of the border had started to take some tentative steps. There was the establishment of the Good Practice Projects across England and Wales, the National Advisory Centre for Early Language Learning, research commissioned by QCA into the present position in England and Wales, the publication of QCA guidelines and a detailed scheme of work for key stage 2. Finally, in 2002 with the publication of the National Strategy for Languages, the government gave an indication that over the next ten years it wished to go much further in terms of primary languages in England and Wales. With the National Strategy for Languages the government aimed to:

- improve the teaching and learning of languages including an entitlement to language learning for pupils at key stage 2 and ensuring that an opportunity to learn languages had a key place in the transformed secondary school of the future;

- introduce a voluntary recognition system to give people credit for their language skills;

- increase the number of people studying languages in further and higher education and in work-based training.

In terms of primary schools, the strategy was in favour of embedding the FL into the primary curriculum. It also recognised the benefits which different types of teachers could bring to the pupils' experience, including native speakers, and aimed to develop training opportunities which would help people with existing language skills to gain additional teaching skills and be recognised to work with teachers in the classrooms.

Although with regard to the primary sector the National Strategy took a positive view of the future of languages in England, intentions for key stage 4 were quite the opposite. As a follow up to the publication of the green paper 14-19: Extending Opportunities, Raising Standards (DfES, 2002a) which provided greater flexibility in the curriculum, the National Strategy stated that at key stage 4 "schools will no longer be required to teach modern Foreign Languages to all pupils" (DfES, 2002a). Unfortunately, this could have implications for the foreign language competence of English pupils and future teachers. The contrasting strategies in the two countries were evident. Whereas Scotland had embarked on primary languages in an attempt to extend provision (covering ages 9-16), the strategy in England was to extend provision to the primary school but to make FLs optional from age 14 .

Whatever the overall strategy for primary languages, there are many crucial issues still to be considered and some key lessons to be learned. There is a need for further debate regarding the aims and objectives appropriate to this age group and the balance of skills.

\section{AIMS AND OBJECTIVES}

To the outsider, England is still experimenting with its aims. Johnstone (1994) identified 5 models for MLPS generally:

“The
contrasting
strategies in
the two
countries were
evident.
Whereas
Scotland had
embarked on
primary
languages in an
attempt to
extend
provision, the
strategy in
England was to
extend
provision to the
primary school
but to make
FLs optional
from age 14"


- encounter;

- subject teaching;

- embedding;

- immersion.

Language awareness is where children are exposed to different languages with a view to showing them how language works rather than developing specific competence within one or more languages. The encounter model is where pupils learn a little bit of different languages and develop a degree of competence in those languages. Again, the aim is more to develop awareness of language than to develop specific linguistic competence. Both of these models could be classified within what other authors refer to as sensitisation, or what the French refer to as 'sensibilisation'. The third model, subject teaching, is the model most frequently to be found within the Scottish context. In this, the aim is to take one language and to develop the child's linguistic competence in that language, to extend the provision of that language over a greater period of time. Embedding is where the language work is embedded within other curricular areas. This does not mean teaching the area itself through the medium of the foreign language, but relating the language work to other work which is in progress. To take the example of the study of the European Union, the language work relating to that study would be the countries or the colours of flags of those countries. The fifth model is immersion, where subjects are taught through the medium of the foreign language. This method is to be found in Canada and also, for example, in Scotland in Gaelic-medium teaching.

Although these broad areas are widely accepted and Driscoll and Frost (1999) refer to a continuum from language awareness programmes through sensitisation to language acquisition programmes, the aims may still vary within these models and include developing skills and positive attitudes to language learning. Trim (1997) talks of how modern language work contributes to the general education of the young child and can enable him/her to develop a positive attitude towards language and towards other ways of thought and other cultures.

Continental writers, for example the Spaniard Tost Planet (1997), place more stress on the development of intercultural competence, which is a respect for and understanding of other cultures and of diversity. Tost Planet also sees the aims as not to teach the foreign language, but how to communicate in a foreign language or to generate in the children an essentially positive attitude towards language learning.

This debate about the aims of MLPS continues in the UK and across Europe. The Norwegian Ytreberg (1997) sees language learning as a main aim, but draws attention to the need for fluency rather than accuracy. The Dutch writer Edelenbos, in Doyé and Hurrell (1997), like the Scots, is definite about the aim being linguistic competence and argues that language awareness may be a first step but is not sufficient in itself. Within this European context the QCA in England considered two reports which it commissioned. Martin (2000) outlines all these aims but also raises the aim of partial linguistic competence. This might be appropriate in an English-speaking context like the UK and the aim might be seen to become an "intercultural speaker" replacing the current emphasis on "native-like" speaker. One might argue that this could also be appropriate in Scotland, which has already chosen the linguistic competence route.

Powell's (2000) study of the situation in England also highlights the diversity of aims. Questionnaires and interviews with primary and secondary teachers and primary headteachers revealed different aims with consequences for the approaches adopted. Powell found that most people see the aim as developing linguistic competence but that they also rate cultural awareness, language learning skills and broadening experience. Initial teacher educators attach greater importance to cultural awareness and extending competence in English. Whereas primary teachers generally place greater emphasis on developing literacy in English, some secondary linguists saw the aims as pupils enjoying language learning and looking forward to continuing at key stage 3 with "basic skills of listening and speaking already mastered" (Powell 2000). Thus across Europe a commonality and diversity of aims is highlighted. As Blondin (1997) points out, “A great deal has been written on the subject, from which it has become clear that nothing seems to have been definitively settled."

\section{AGE}

If there is no consensus about aims, the major argument probably relates to age. Is it advantageous to start at primary school or are older learners more effective? Trim (1997) rehearses the arguments about a critical period where the "plasticity of the brain" uniquely favours language acquisition, but he also feels that in most respects older learners are more efficient. Penfield and Roberts (1959) put forward a neuro-physiological argument that the brain becomes "progressively stiff and rigid after the age of 9". However, Van Parreren (1976) counters this and claims that the early "plasticity" can be compensated by the older child's learning strategies. MarinovaTodd (2000) claims that

although older learners are indeed less likely than young children to master an L2, a close examination of studies relating age to language acquisition reveals that age differences reflect differences in the situation of learning rather than in capacity to learn.

Marinova-Todd (2000) points out that psycholinguists generally accept that a critical period for L1 acquisition exists, but that there is controversy when the critical period claim is extended to L2 learning and concludes from analysis of the critical period research that

older learners have the potential to learn L2s to a very high level and that introducing foreign languages to very young learners cannot be 
justified on grounds of biological readiness to learn languages.

Other researchers put forward different arguments in favour. Some point to socialisation and integration as factors which make the child more "closed" as an individual as he/she becomes older. Others, like Stern (1969), make a pedagogical case, arguing that education for living must take account of other languages and cultures from the earliest stage.

Of course other studies find against an optimum age. Poole (1999) aimed to ascertain whether 'younger was better' in terms of FL teaching. She compared 2 schools that had different socioeconomic backgrounds and used different teacher models (a non-specialist class teacher versus a visiting French qualified teacher) and different methods (concentration on the spoken word with "no explicit teaching of formal aspects of language" versus teaching including "some explicit grammar teaching"). She found a number of reasons that would not support the early introduction of MLPS:

- pupils had problems "adapting pre-rehearsed language chunks to new situations or to create novel utterances";

- pupils had problems asking questions;

- they had poor listening skills;

- they had difficulties reading, writing and with numbers.

Poole found that younger pupils were more confident and enthusiastic than older ones, but this could have been due to the 'fun' approach that focused mainly on "imitation and reproduction rather than on production" and there was no link between the pupils' ability in the FL and their enthusiasm. She concluded that at an early age it could be more beneficial to concentrate on a 'learning how to learn' approach, rather than one based on 'learning a FL'.

Doyé and Hurrell (1997) argue for the desirability of an early start, and Martin (2000) considers the arguments on both sides and is persuaded of the balance in favour. We would agree that the balance is in favour but do not believe that there is a consensus. The points in favour are:

- the pupils' enthusiasm and capacity for enjoyment;

- their willingness to take risks and make errors work for them;

- their low "affective filter".

The authors' observations of 200 classes in Scotland would support these specific points. The children observed were certainly more willing to have a go, were less self-conscious than adolescents, and their accent and pronunciation were well developed. Younger learners are naturally less apprehensive, less worried than teenagers about making mistakes, and this is a considerable factor. This may support the case for the dominance of an aural/oral approach in early language learning and could avoid the situation where adolescents encounter a new subject in which they are expected to "perform" at a time when they are most self-conscious. We believe the points about age are crucial in deciding how and what we teach at a younger age in both countries.

\section{BENEFITS}

In considering our aims, therefore, it would seem appropriate to focus particularly on the benefits of an early start. Many have argued that the "affective filter" (Krashen, 1984) is deactivated among primary age children and how they are more comfortable in a language learning environment. Martin's (2000) analysis points to benefits in terms of their intuitive approach to learning, their speed of recall and better pronunciation. Johnstone (1994) notes that this advantage is identified in the research into the Scottish Pilot programme in the early 90s. That research also identified the benefits of a positive attitude, a willingness to take risks and the use of "repair strategies". The Croatian Vilke (1998) argues that the early start helps children acquire good command of sounds. Other writers also claim that young children appear to have a special facility for acquiring the sound system of a foreign language almost to native speaker level. Thus the case for work in this area is extremely convincing and we would argue that this be a top priority for MLPS work.

Powell's study (2000) notes certain benefits based on the impressions of the teachers, such as increased motivation, enthusiasm and a developing confidence. Primary teachers were unanimous about the benefits in terms of confidence, increased attention span, interests in other cultures and positive attitudes to language learning. Heads of Department in English secondaries also noted pupil confidence, improved listening skills, no fear or panic and better reading, but there was little impact on writing. Powell also found that $72 \%$ of secondary linguists surveyed agreed that "languages in primary schools increase pupils' motivation to learn foreign languages at secondary school."

Nisbet and Welsh (1972) also support the argument that a major benefit of the early start is a positive attitude to language learning. Their study found that a higher proportion continued with their studies in S3. Blondin also points out that all studies show a positive effect in terms of attitude to languages, culture and language learning.

In Scotland, it is interesting to note a reversal in the decline of students continuing their language study post 16 as numerically significant cohorts who experienced MLPS reach that stage. However, this could also be attributed to Higher Still or other factors. The observations made by one of the authors in his capacity as National Development Officer would support the views about attitude and motivation. Only in two of these classes did he encounter a negative attitude and he would attribute that to an arid approach in methodology. Thus the benefits, in terms of attitude although not easily measured, might be a crucial factor, but a positive attitude might also be very dependent on an appropriate methodology.

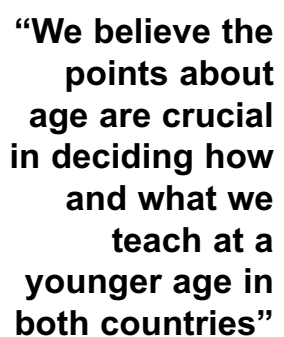




\section{METHODOLOGY}

As outlined earlier there is tremendous diversity of aims, and there is a significant relationship between those aims and the methods employed. Driscoll (1999) points out how a generalist teacher highlighted the importance of pupils' confidence and enjoyment rather than their linguistic competence and planned the lessons accordingly. It is curious that linguistic competence and enjoyment should be seen as mutually exclusive, but this teacher's main aim was for the children to enjoy their language experience. Driscoll also notes other teachers who saw French as "light relief after a morning of preparation for SAT tests". Her observation of lessons saw many which were full of movement, with children out of their seats and playing games.

In Italy (Taeschner, 1991) a more conventional approach led to demotivation, whereas an Austrian study (Gangl, 1997) stresses the advantage of an interactive approach compared to another trial study using conventional methods. Mayo (1996) argued for numerous, quick activities which involve movement and song. Ytreberg (1997) goes further, arguing that children should use all faculties and learn by playing and that grammar has little purpose in the early stages. Many other writers advocate songs, stories, noise, movement and a multi-sensory approach. In Catalonia much work is based on practical arts, P.E., dance and psychomotor activity.

These activities were also much in evidence in the Pilot Project in Scotland. At the generalisation stage much was made of a "fun approach" in MLPS. As MLPS has now become formalised in the 5-14 programme and a definite entitlement has been outlined by the Minister, some local authority Advisers report a difficulty in motivating teachers who feel that "the goalposts have been moved" in terms of reading and writing and knowledge about language. Some secondary linguists involved in the Pilot were already starting to question the approach. Wolfe (1996) pointed out that secondary pupils were unable to learn thoroughly or complete tasks with urgency. She also identified reluctance to learn spelling and structures. Furthermore Wolfe argues that

a balance in favour of listening and speaking as perceived in the initial guidelines should be tilted back by developing a greater awareness of the connection between sound and spelling.

That brings us back to the diversity of aims and to two other specific issues: the extent to which language structures should be developed and the balance of the 4 skill areas of speaking, listening, reading and writing.

\section{KNOWING ABOUT LANGUAGE (KAL)}

As Wolfe (1996) points out, teaching or even talking about grammar had been discouraged by those directing the Pilot Project. This related to the encouragement of the fun element allied to avoiding anxiety among pupils. It was therefore perhaps not surprising that Low (1995) in the Pilot Research Report drew attention to pupils' inability to create utterances. They were unable to manipulate language, and there had been a lack of explicit comparison of the foreign language and first language. This was not a new situation. In 1969, a study of 325 classes by HMI in Scotland had led to disappointment at the lack of ability to transfer language to new situations. Driscoll (1999) also observes that predictable routines were facilitated by rote learning but that pupils were unable to extend their language.

Following the Scottish Pilot, the argument was made that pupils' learning is intuitive and that they absorb 'chunks of language' but this needs to be followed by a more analytical, reflective approach.

However, Powell's (2000) recent survey of the situation in England also points to a limited range of strategies and the lack of opportunity for pupils to reuse language. With the extension of MLPS in Scotland there has certainly been a shift and an encouragement to develop knowledge about language but the impression gained to date has been that the situation is patchy within Scotland. The question needs to be asked: Are we in danger of repeating that old error in both England and Scotland?

\section{THE FOUR SKILLS}

It is also important that policy makers consider the debate on the four skills. There are conflicting views on whether we should be concentrating on oral/ aural work at primary level or whether these skills should be complemented by reading and writing. There seems to be general support for the argument that children at this stage have a particular facility for pronunciation and accent. Mitchell, Martin and Grenfell (1992), in considering the age factor, concluded that research had not demonstrated beyond doubt that young learners were more effective "with the possible exception of pronunciation".

Martin (2000) concludes that there is definite evidence that younger children do better "as regards the development of the phonological system". There is also support for this argument from Edelenbos and Hurrell (1997), who point to agreement about an early start based on "a seemingly intrinsic capacity of the young learner to acquire the sound system."

However, a study cited in Marinova-Todd (2000):

demonstrated that adult learners could attain native-like pronunciation in the target language after experiencing a silent period during which they were asked to listen to L2 speech without speaking it (conditions replicating the learning situation of young children).

Perhaps it is the approach to the development of pronunciation at this stage rather than "intrinsic capacity".

Singleton (1989) and Hawkins (1987) also point to evidence of superiority in oral / aural performance 
among young learners. Scottish pupils in the Pilot Project were required to say very little and were able to understand large chunks of language without being able to analyse it. In the Netherlands "strikingly good results for listening" were identified by Edelenbos, but there is considerable exposure to English outside school as well in the Netherlands. Many of these arguments might have led to the dominance of an oral / aural approach in the Scottish context. The 'fun' argument is the one which is most often heard, and indeed there is an assumption that pupils do not enjoy writing.

On the issue of reading and writing there is little agreement. Some argue that a wholly oral/aural approach is possible for a longer period at this stage and allows more pupils to succeed. Others make a counter-argument that the attention span of younger pupils is limited. Some would exclude writing altogether. However, might writing not help children consolidate their learning, to memorise chunks of language and be able to reproduce these? Might it make them more effective learners?

The contrasting views are highlighted in Hurrell (1996), where a teacher in England writes that the course emphasised listening and speaking and that that gave children "a welcome break from pencil and paper work". A teacher in Scotland then argues that children need the written word to consolidate their learning and that his school is "working on establishing a sound knowledge of the relationship between the written and spoken word". This difference is highlighted in two counties in the South-East of England. Driscoll (1999) found that the specialist teacher introduced the four skills whereas the generalist focused mainly on listening and speaking. Some schools visited by the present authors in Scotland did no writing but others worked on the relationship between the spoken and written word in a systematic fashion. However, there is no current evidence of the approach generally and we do not know if the 5-14 guidelines have changed the situation.

Elsewhere in Europe (Blondin et al. 1997) the situation is also confused. A Dutch study points to performance in listening, speaking, reading with no mention of writing. A Swedish study states that listening is satisfactory and speaking less so, but reading and writing are not mentioned. A study in France showed a slight advantage in listening, reading and writing but only among the best pupils, and it disappeared after one year. In Germany, it was noted that the gap between weaker and stronger children was hidden because of the oral / aural approach.

In the UK it is often claimed that children do not like or need to write, but there is no evidence to support this view. However, Russell (1970) points out that after three or four terms of purely oral work "pupils were desperate for printed materials to help them memorise what they had covered orally". Powell points to a case study where reading cards did not affect pupils' pronunciation negatively and in fact built up their confidence and provided support. It might be argued that copy writing, combined with developing awareness of the sound system, might also aid confidence.

These are important issues and we need to agree on a way forward. Should we omit reading and writing at this stage or are they also vital skills to consolidate the child's linguistic experience? On balance, the present authors' view is that the four skills should be developed at this stage, although an aural-oral approach will continue to dominate. However, there is no consensus on whether this is the correct approach.

\section{CONCLUSION}

Significant funding has been invested in MLPS in Scotland and is increasing in England. Whereas in Scotland aims have been clearly defined, England has been experimenting with different approaches. In both countries serious consideration needs to be given to the key benefits and the consequences for methodology. We would again highlight the development of pronunciation, an awareness of the sound system and developing knowledge about language and the ability to manipulate 'chunks of language'. There is considerable agreement about an interactive approach and much is made of the 'fun' element, as can be seen in the context of developing positive attitudes. However, the balance of skills remains tied up with the aims and objectives, and there is no agreement about the skills of reading and writing.

The whole issue of continuity is also crucial, and early language in itself is not the whole answer. As Marinova-Todd (2000) points out:

Research has shown that in formal settings early L2 instruction does not prove advantageous unless followed by well designed foreign language instruction building on previous learning. Children who study a foreign language for only a year or two in elementary school show no long-term effects; they need several years of continued instruction to achieve even modest proficiency.

We are entering a crucial phase in MLPS within these islands, and there is a need for a national debate involving all stakeholders so that a clear strategy can be mapped out.

\section{BIBLIOGRAPHY}

Blondin, C et al. (1997) Foreign Languages in Primary and Pre-School Education: Context and Outcomes. A Review of Recent Research within the European Union. Brussels: The European Commission.

Burstall, C. et al (1974) Primary French in the Balance. Windsor: NFER.

DfES (2002) Languages for All: Languages for life. A Strategy for England. Nottingham: DfES Publications.

DfES (2002a) 14-19: Extending Opportunities, Raising Standards. London: DfES. Available at http://www.dfes.gov.uk/14-19greenpaper/download/ raisingstandards.pdf

DfES (2002b) Languages for All: Languages for Life. A Strategy for England. London: DfES. Available at http://www.dfes.gov.uk/languagesstrategy

Doyé, P and Hurrell, A (1997) Foreign Language Learning in Primary Schools. Strasbourg: The Council of Europe.

Driscoll, P and Frost, D. (eds) (1999) The Teaching of Modern Foreign Languages in the Primary School. London: Routledge. 
HMSO (1998) Standards and Quality in Primary and Secondary Schools: 1994 - 98: Modern Languages. Edinburgh: HMSO

Gangl, R (1997), "Learning Through Interaction - A Discourse Model for FLT to Primaries", Unpublished Doctoral Thesis, Karl-Franzens-Universität, Graz.

Hurrell, A and Satchwell, P. (eds) (1996) Reflections on Modern Languages in Primary Education. London: The Centre for Information on Language Teaching.

Johnstone, R. (1994) Teaching Modern Languages at Primary School, Edinburgh: The Scottish Council for Research in Education.

Krashen, S. (1984) Principles and Practice in Second Language Acquisition. Oxford: Pergamon Press.

Learning and Teaching Scotland (2000) Modern Languages 514 National Guidelines. Dundee: Learning and Teaching Scotland.

Low, L., Brown, S., Johnstone, R.M. and Pirrie, A. (1995) Foreign Languages in Primary Schools: Evaluation of the Scottish Pilot Projects: 1993 - 98. Final Report, University of Stirling: Scottish CILT.

Marinova-Todd, S.H., Bradford Marshall, D., Snow, C. E. (2000) Three Misconceptions about Age and L2 Learning, TESOL Quarterly vol.34, No 1.

Martin, C (2000) An Analysis of National and International Research on the Provision of Modern Foreign Languages in Primary Schools. London: Qualifications and Curriculum Authority.

Mayo, J. (1996) in Hurrell, A. and Satchwell, P. (eds) Reflections on Modern Languages in Primary Education, London: The Centre for Information on Language Teaching.

Mitchell, Martin and Grenfell (1992) Evaluation of the Basingstoke Primary Schools Language Awareness Project for Language Education, University of Southampton.

Nisbet, J. and Welsh, J. (1972) A local evaluation of Primary School French In: Entwistle, N. and Nisbet, J., Educational Research in Action. London: Open University, University of London Press.

Pachler, N. (2002) Foreign language learning in England in the $21^{\text {st }}$ century. Language Learning Journal, 25. pp.4-7

Penfield, W. and Roberts, L. (1959) Speech and Brain Mechanisms. Princeton: University Press.

Poole, B. (1999) "Is Younger Better?" A critical examination of the beliefs about learning a foreign language at primary school, unpublished doctoral disertation. Institute of Education, University of London.

Powell, B et al (2000) Analysis and Evaluation of the Current Situation Relating to the Teaching of Modern Foreign Languages at Key Stage 2 in England. London: Qualifications and Curriculum Authority.

Schools Council (1966) French in the Primary School; Working Paper n.8

Scottish Executive (2000): Citizens of a Multilingual World. Edinburgh: Scottish Executive.

Scottish Executive (2003) AAP: Report of the First Survey of Modern Languages (French and German) 2001. Edinburgh: Scottish Executive.

Scottish Office (1989) Education and Industry Department: Circular 1178. Edinburgh: Scottish Office.

Scottish Office (1993) Education and Industry Department, January. Edinburgh: Scottish Office.

Sharpe, K. (2001) Modern Foreign Languages in Primary School; the what, why and how of early MFL teaching. Koogan Page, London.

Singleton, D. (1989) Language Acquisition: the age factor. Clevedon: Multilingual Matters.

Stern, H.H. (ed) (1969) Languages and the Young School Child. Oxford: Oxford University Press.

Taeschner, T. (1991) A Developmental Psycholinguistic Approach to Second Language Teaching. Ablex: Norwood.

Tost Planet, M. (1997) in Doyé, P. and Hurrell, A., Foreign Language Learning in Primary Schools. Strasbourg: the Council of Europe.

Trim, J. (1997) in Doyé, P. and Hurrell A., Foreign Language Learning in Primary Schools. Strasbourg: Council of Europe.

Ytreberg, L. (1997) in Doyé, P. and Hurrell, A., Foreign Language Learning in Primary Schools Strasbourg: Council of Europe.

Van Parreren, C. (1976). The psychological aspects of the early teaching of Modern Languages, IRAL 14, 135 - 142

Vilke (1998) Some psychological aspects of early second language acquisition, Journal of Multilingual and Multicultural Development, 9, 1 and 2.

Wolfe, L. (1996) in Hurrell, A. (1996) and Satchwell, P. ed. Reflections on Modern Languages in Primary Education. London: The Centre for Information on Language Teaching. 